CLINICAL STUDY

\title{
Early or advanced stage type 2 diabetes is not accompanied by in vivo skeletal muscle mitochondrial dysfunction
}

\author{
H M De Feyter, N M A van den Broek, S F E Praet ${ }^{1}$, K Nicolay, L J C van Loon ${ }^{1}$ and J J Prompers \\ Biomedical NMR, Department of Biomedical Engineering, Eindhoven University of Technology, PO Box 513, 5600 MB Eindhoven, \\ The Netherlands and ${ }^{1}$ Department of Movement Sciences, Nutrition and Toxicology Research Institute Maastricht (NUTRIM), Maastricht University, \\ PO Box 616, 6200 MD Maastricht, The Netherlands \\ (Correspondence should be addressed to J J Prompers; Email: j.j.prompers@tue.nl)
}

\begin{abstract}
Objective: Several lines of evidence support a potential role of skeletal muscle mitochondrial dysfunction in the pathogenesis of insulin resistance and/or type 2 diabetes. However, it remains to be established whether mitochondrial dysfunction represents either cause or consequence of the disease. We examined in vivo skeletal muscle mitochondrial function in early and advanced stages of type 2 diabetes, with the aim to gain insight in the proposed role of mitochondrial dysfunction in the aetiology of insulin resistance and/or type 2 diabetes.

Methods: Ten long-standing, insulin-treated type 2 diabetes patients, 11 subjects with impaired fasting glucose, impaired glucose tolerance and/or recently diagnosed type 2 diabetes, and 12 healthy, normoglycaemic controls, matched for age and body composition and with low habitual physical activity levels were studied. In vivo mitochondrial function of the vastus lateralis muscle was evaluated from post-exercise phosphocreatine $(\mathrm{PCr})$ recovery kinetics using ${ }^{31} \mathrm{P}$ magnetic resonance spectroscopy (MRS). Intramyocellular lipid (IMCL) content was assessed in the same muscle using single-voxel ${ }^{1} \mathrm{H}$ MRS.

Results: IMCL content tended to be higher in the type 2 diabetes patients when compared with normoglycaemic controls $(P=0.06)$. The ${ }^{31} \mathrm{P}$ MRS parameters for mitochondrial function, i.e. $\mathrm{PCr}$ and ADP recovery time constants and maximum aerobic capacity, did not differ between groups.

Conclusions: The finding that in vivo skeletal muscle oxidative capacity does not differ between longstanding, insulin-treated type 2 diabetes patients, subjects with early stage type 2 diabetes and sedentary, normoglycaemic controls suggests that mitochondrial dysfunction does not necessarily represent either cause or consequence of insulin resistance and/or type 2 diabetes.
\end{abstract}

European Journal of Endocrinology 158 643-653

\section{Introduction}

Insulin resistance is an early event in the pathogenesis of type 2 diabetes. However, the exact processes leading to insulin resistance remain unresolved. Previous studies have reported a strong correlation between intramyocellular lipid (IMCL) content and insulin resistance $(1,2)$. However, the proposed relationship between IMCL accumulation and skeletal muscle insulin resistance is not unambiguous, as it is strongly influenced by training status and/or habitual physical activity $(3,4)$. Nonetheless, several lines of evidence indicate that mitochondrial dysfunction, presumably associated with a reduced capacity to oxidize fatty acids, might stimulate IMCL accretion and, as such, contribute to the development of skeletal muscle insulin resistance (5).

Data to support the proposed role of skeletal muscle mitochondrial dysfunction in the development of insulin resistance and/or type 2 diabetes have been obtained with various in vitro methods, including measurements of oxidative enzyme activities (6-10), mRNA and/or protein expression of oxidative phosphorylation genes (10-14) as well as mitochondrial content, morphology and respiration $(8,9,14,15)$. Furthermore, in vivo magnetic resonance spectroscopy (MRS) measurements of basal mitochondrial ATP synthesis rates (16-18) and post-exercise phosphocreatine (PCr) (19) and ADP (20) recovery kinetics also point towards a potential role for mitochondrial dysfunction in the aetiology of insulin resistance and/ or type 2 diabetes. However, it was recently shown that in vitro mitochondrial respiration of permeabilized muscle fibres from biopsies of the type 2 diabetes patients and healthy controls did not differ between groups when the data were normalized for mitochondrial DNA content or citrate synthase activity (21). In other words, the type 2 diabetes patients showed normal intrinsic mitochondrial function, but an impaired oxidative capacity that was entirely attributed to a lower mitochondrial content. Environmental 
factors play an important role in regulating skeletal muscle oxidative capacity, and the lower mitochondrial content in the type 2 diabetes patients might simply be the result of a reduced habitual physical activity level (21-23). Furthermore, mitochondrial dysfunction in type 2 diabetes might be secondary to impaired insulin signalling (24-26) and/or abnormal blood glucose, insulin $(27,28)$ and non-esterified fatty acid (NEFA) (26) levels. Therefore, the debate continues as to whether mitochondrial dysfunction represents either cause or consequence of insulin resistance and/or type 2 diabetes.

The aim of this study was to assess whether in vivo mitochondrial function is impaired in the early and/or overt diabetes state. Therefore, we examined in vivo muscle mitochondrial function in three groups of subjects, representative for different stages in the development of type 2 diabetes: long-standing, insulintreated type 2 diabetes patients, subjects with impaired fasting glucose, impaired glucose tolerance and/or recently diagnosed type 2 diabetes, and healthy, normoglycaemic controls, all matched for age and body composition and with low habitual physical activity levels. In vivo mitochondrial function was determined from post-exercise $\mathrm{PCr}$ recovery kinetics measured with ${ }^{31} \mathrm{P}$ MRS (29-31).

\section{Materials and methods}

\section{Subjects}

Ten long-standing, insulin-treated type 2 diabetes patients (Diabetes group), 11 subjects with impaired fasting glucose, impaired glucose tolerance and/or recently diagnosed type 2 diabetes (pre-Diabetes group), and 12 healthy, normoglycaemic controls (Control group) were selected to participate in this study. All subjects were male. The diabetes patients had been diagnosed with type 2 diabetes for over 5 years, established by a fasting plasma glucose concentration larger than or equal to $7.0 \mathrm{mmol} / \mathrm{l}$ at the time of diagnosis as defined by the World Health Organization (WHO) (32). Subjects in the Control and preDiabetes groups had no family history of diabetes and were selected based on an oral glucose tolerance test (OGTT) according to the WHO criteria (32). Control subjects showed normal fasting glucose concentrations and normal glucose tolerance (fasting glucose $<6.1 \mathrm{mmol} / \mathrm{l}$ and $2-\mathrm{h}$ glucose $<7.8 \mathrm{mmol} / \mathrm{l}$ ). Subjects in the pre-Diabetes group had either elevated fasting plasma glucose concentrations (fasting glucose $\geq 6.1$ and $<7.0 \mathrm{mmol} / \mathrm{l}$, and $2-\mathrm{h}$ glucose $<7.8 \mathrm{mmol} / \mathrm{l}$; $n=5$ ), or impaired glucose tolerance (fasting glucose $<7.0 \mathrm{mmol} / \mathrm{l}$, and 2 -h glucose $\geq 7.8$ and $<11.1 \mathrm{mmol} / \mathrm{l} ; n=2$ ), or recently diagnosed type 2 diabetes $(<1 \mathrm{month}$; fasting glucose $\geq 7.0 \mathrm{mmol} / \mathrm{l}$ or 2-h glucose $\geq 11.1 \mathrm{mmol} / \mathrm{l} ; n=4$ ).
All diabetes patients were on exogenous insulin treatment and had been on a stable regimen of diabetes medication over the last 3 months before being recruited. Out of the ten participating diabetes patients, seven patients were treated with short (Novorapid ${ }^{\circledR}$, $n=6$ ) or rapid acting insulin (Humulin ${ }^{\circledR}, n=1$ ) before each meal either in combination with NPH insulin (Insulatard $\left.{ }^{\circledR}, n=5\right)$, premixed biphasic isophane insulin (Mixtard $30 / 70^{\circledR}$ in combination with metformin, $n=1$ ), or a very long-acting insulin analogue (insulin glargine, $n=1$ ), all administered before bedtime. Two patients were treated with premixed biphasic isophane insulin (Mixtard 30/70 ${ }^{\circledR}$ ) twice a day in combination with metformin. One patient used NPH insulin (Humulin $\mathrm{NPH}^{\circledR}$ ) once a day before breakfast in combination with metformin and a sulphonylurea (glimepiride). Patients using thiazolidinediones were excluded from participation. None of the subjects in the pre-Diabetes group used blood glucose-lowering medication and all showed glycosylated haemoglobin $\left(\mathrm{HbA}_{1 \mathrm{c}}\right)$ contents below $6 \%$. Subjects using $\beta$-blockers for less than 6 months and subjects with impaired liver function, renal failure, severe retinopathy or a history of severe cardiovascular problems were excluded from participation. Subjects with clinical signs of peripheral vascular disease (Fontaine stage II or higher) were excluded based on a thorough history considering signs of intermittent claudication, as well as a physical examination of the peripheral vascular system (no arterial bruits over the abdominal aorta, iliac artery and/or diminished pulses of femoral artery, dorsalis pedis and posterior tibial artery). The nature and the risks of the experimental procedures were explained to the subjects and all gave their written informed consent to participate in the study, which was approved by the local Medical Ethical Committee of the Máxima Medical Centre, Veldhoven, The Netherlands. This study is part of a larger project that studies mitochondrial function in chronic metabolic disease $(33,34)$.

\section{Body composition}

Body mass index (BMI) and waist circumference were measured using an analogue weight scale and standard measuring tape. Whole-body fat-free mass (FFM) and truncal fat mass were determined using whole-body dual energy X-ray absorptiometry (Hologic QDR-4500 Discovery A, software version 12.3.3, Hologic Inc., Bedford, MA, USA).

\section{Habitual physical activity level}

Habitual physical activity level was assessed with the Tecumseh and Minnesota occupational and leisure time activity questionnaire (35). The activity level was expressed in metabolic equivalents (MET), which is a scale of the energy cost of various physical activities in multiples of the resting metabolic rate. 


\section{Whole-body oxygen uptake capacity}

Maximal whole-body oxygen uptake capacity $\left(\mathrm{VO}_{2 \text { peak }}\right)$ and maximal workload capacity $\left(W_{\text {max }}\right)$ were measured during an incremental exercise test until exhaustion, performed on a cycle ergometer (Medifit Ergometer, Medifit systems, Maarn, The Netherlands) using a ramp protocol (36). Gas exchange measurements were performed continuously (Ergostar II, PMS Professional Medical Systems, Basel, Switzerland). Maximal wholebody oxygen uptake capacity was defined as the $\mathrm{VO}_{2}$ value remaining unchanged or increasing at $<1 \mathrm{ml} / \mathrm{min}$ per $\mathrm{kg}$ for $30 \mathrm{~s}$ or more despite an increment in workload (37). Cardiac function was monitored using a 12-lead electrocardiogram with heart rate being recorded continuously (Polar Electro, Kempele, Finland). The age-predicted maximal heart rate was calculated according to the prediction model of Gellish et al. (38).

\section{Blood sampling and analyses}

Subjects reported at the laboratory at $0800 \mathrm{~h}$ after an overnight fast. After $5-10 \mathrm{~min}$ of supine rest, fasting samples of venous blood were collected from an antecubital vein. Subsequently, a standard OGTT was performed for all subjects, except for the diabetes patients, and blood samples were collected $2 \mathrm{~h}$ after ingestion of the glucose load. Blood plasma samples were collected into EDTA-containing tubes and centrifuged for $10 \mathrm{~min}$ at $4^{\circ} \mathrm{C}$. Aliquots of plasma were frozen immediately in liquid nitrogen and stored at $-80{ }^{\circ} \mathrm{C}$ until further analyses. Plasma concentrations of glucose (Roche) and NEFA (Wako Chemicals, Neuss, Germany) were analysed with a COBAS semi-automatic analyzer (Roche). Plasma insulin was determined in duplicate by RIA (Linco, St Charles, MO, USA) for Control and pre-Diabetes groups. Cross sensitivity of exogenously administered insulin with this RIA prohibited the detection of endogenously produced insulin in the insulin-treated diabetes patients. The blood $\mathrm{HbA}_{1 \mathrm{c}}$ content was analysed by HPLC (Bio-Rad Diamat). For the Control and pre-Diabetes groups, the homeostasis model assessment (HOMA) index (39) was calculated.

\section{MRS measurements}

MRS measurements were performed with an $1.5 \mathrm{~T}$ whole-body scanner (Gyroscan S15/ACS, Philips Medical Systems, Best, The Netherlands) during two sessions. On the evening before the first MRS session, subjects received a standardized meal (mean \pm s.D.: $41.0 \pm 15.1 \mathrm{~kJ}$ per $\mathrm{kg}$ body weight, containing 40.7 energy\% (En\%) fat, 14.6 En\% protein and $44.7 \mathrm{En} \%$ carbohydrate) after which subjects remained fasted and were allowed to drink water only. Subjects travelled by car or public transport and reported at the laboratory at $0830 \mathrm{~h}$, where they received a standardized breakfast. First, ${ }^{1} \mathrm{H}$ MRS measurements were performed for the quantification of IMCL. After a short break, the ${ }^{31} \mathrm{P}$ MRS protocol was carried out to familiarize the subjects to the in-magnet exercise and to determine the optimal exercise intensity for the second visit. During the second MRS session, scheduled within 1 week, ${ }^{31} \mathrm{P}$ MRS measurements were performed to assess skeletal muscle mitochondrial function. For the diabetes patients, blood glucose-lowering medication was not withdrawn before the MRS measurements.

\section{${ }^{1} \mathrm{H}$ MRS}

IMCL was measured in the Musculus vastus lateralis with image-guided single-voxel ${ }^{1} \mathrm{H}$ MRS using the body coil for transmission and an $8 \mathrm{~cm}$ diameter surface coil for signal reception. For each subject, five voxels with a size of $10 \times$ $10 \times 15 \mathrm{~mm}^{3}$ were measured at different positions within the $M$. vastus lateralis. The voxels were carefully placed to avoid subcutaneous and visible interstitial fat using standard $\mathrm{T}_{1}$-weighted images (Fig. 1A). Spectra were recorded with a point-resolved spectroscopy (PRESS) sequence (repetition time, $1500 \mathrm{~ms}$; echo time, $35 \mathrm{~ms}$; spectral width, $2000 \mathrm{~Hz}$; number of data points, 2048; 128 averages) using chemical-shiftselective saturation for water suppression. Unsuppressed water spectra (32 averages) were recorded from the same voxels and used as an internal reference.

\section{${ }^{1}$ H MRS data analysis}

All spectra were fitted in the time domain by using a non-linear least-squares algorithm (AMARES) in the jMRUI software package (40) without further postprocessing, except for manual phasing. The unsuppressed water spectrum was phased and fitted to a Lorentzian line shape. The zero-order phase correction from the water spectrum was applied to the corresponding water-suppressed spectrum and the total creatine (tCr) $\mathrm{CH}_{3}$ peak was referenced to $3.02 \mathrm{ppm}$. In the water-suppressed spectrum, peaks from trimethyl ammonium and $\mathrm{tCr} \mathrm{CH}_{3}$, extramyocellular lipid (EMCL) and IMCL $\mathrm{CH}_{2}$, and EMCL and IMCL $\mathrm{CH}_{3}$ protons (see Fig. 1B) were fitted to the Gaussian line shapes. The positions and areas of the EMCL and IMCL $\mathrm{CH}_{3}$ peaks were constrained with respect to the positions and areas of the EMCL and the IMCL $\mathrm{CH}_{2}$ peaks respectively (41). To increase the reliability of the fit, the linewidth of the IMCL $\mathrm{CH}_{2}$ peak $\left(\mathrm{LW}_{\text {IMCL }}\right)$ was constrained with respect to the linewidth of the water peak $\mathrm{LW}_{\mathrm{H}_{2} \mathrm{O}}$ according to

$$
\mathrm{LW}_{\mathrm{IMCL}}=-0.09+1.02 \cdot \mathrm{LW}_{\mathrm{H}_{2} \mathrm{O}}
$$

This constraint was derived from previously recorded data sets with a well-resolved IMCL peak (number of data sets $=20, R=0.821, P<0.0001$ ). A soft constraint that was empirically determined from the previously recorded data sets, was applied to the linewidth of the EMCL $\mathrm{CH}_{2}$ peak ( $\mathrm{LW}_{\mathrm{EMCL}}$ ), 
A

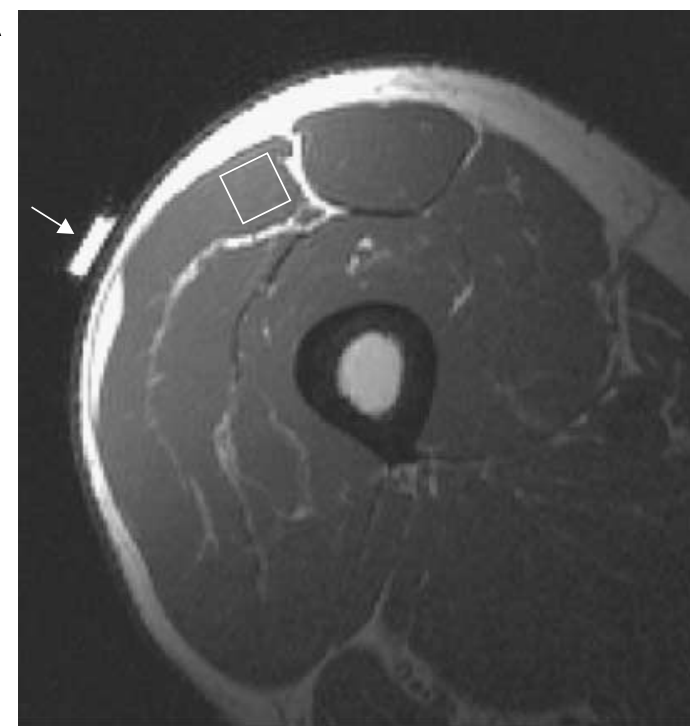

B

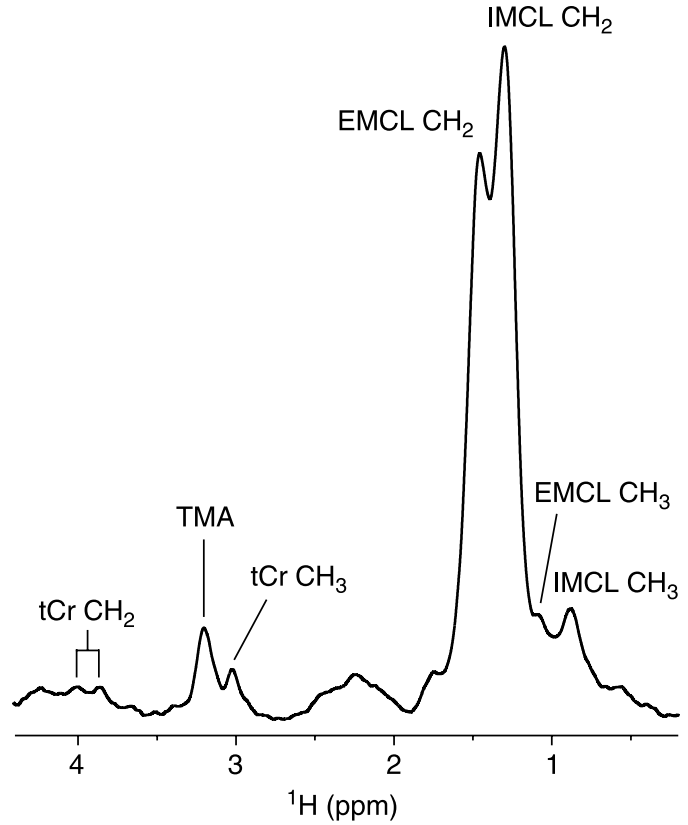

Figure 1 (A) Transversal $T_{1}$-weighted spin-echo image of the upper leg of a type 2 diabetes patient with voxel positioning within the $M$. vastus lateralis for single-voxel ${ }^{1} \mathrm{H}$ MRS. The size of the voxel was $10 \times 10 \times 15 \mathrm{~mm}^{3}$. The arrow points at a phantom that was located in the centre of the $8 \mathrm{~cm}$ diameter surface coil. (B) ${ }^{1} \mathrm{H}$ MR spectrum from the voxel depicted in (A). The spectrum was processed with $1 \mathrm{~Hz}$ line broadening. Peak annotations: $\mathrm{tCr} \mathrm{CH}_{2} / \mathrm{CH}_{3}, \mathrm{CH}_{2} / \mathrm{CH}_{3}$ protons of total creatine; $\mathrm{TMA}, \mathrm{CH}_{3}$ protons of trimethyl ammonium groups; EMCL $\mathrm{CH}_{2} / \mathrm{CH}_{3}, \mathrm{CH}_{2} / \mathrm{CH}_{3}$ protons of extramyocellular lipid, IMCL $\mathrm{CH}_{2} / \mathrm{CH}_{3}, \mathrm{CH}_{2} / \mathrm{CH}_{3}$ protons of intramyocellular lipid.

i.e. $\mathrm{LW}_{\mathrm{EMCL}} \leq \mathrm{LW}_{\mathrm{IMCL}}+3.33 \mathrm{~Hz}$. When the resonance frequency $(\delta)$ of the IMCL $\mathrm{CH}_{2}$ peak could not be accurately fitted (i.e. $\delta \leq 1.25 \mathrm{ppm}$ or $\delta \geq 1.31 \mathrm{ppm}$ ), the position of the IMCL $\mathrm{CH}_{2}$ peak was constrained with respect to the position of the $\mathrm{tCr} \mathrm{CH}_{3}$ peak (chemical shift difference $=3.02-1.28 \mathrm{ppm}$ ). IMCL was expressed as a percentage of the water signal measured in the same voxel without water suppression. The IMCL levels determined from different voxels of one subject were averaged.

\section{P MRS}

${ }^{31} \mathrm{P}$ MRS was performed as described previously (33). In short, ${ }^{31} \mathrm{P}$ signals were collected using a $6 \mathrm{~cm}$ diameter surface coil placed over the M. vastus lateralis (spectral width, $2000 \mathrm{~Hz}$; number of data points, 1024). A fully relaxed spectrum was measured at rest with a repetition time of $30 \mathrm{~s}$ and 24 scans. Then, spectra were acquired during a rest-exercise-recovery protocol with a repetition time of $3 \mathrm{~s}$ and two scans yielding a time resolution of $6 \mathrm{~s}$. The first 20 spectra $(2 \mathrm{~min})$ were measured at rest, after which the subjects started the exercise. Subjects performed a dynamic incremental single-leg extension exercise in the supine position using a homebuilt MR-compatible ergometer (33). The duration of the exercise varied per subject, but never exceeded $8 \mathrm{~min}$, so that at least $5 \mathrm{~min}$ of recovery were recorded. During the first visit, subjects performed a test run and exercised until fatigued. During the second session, the duration of the exercise was chosen to deplete PCr by about $50 \%$, while aiming to avoid the intracellular $\mathrm{pH}$ dropping below 6.8 .

\section{${ }^{31} P$ MRS data analysis}

The ${ }^{31} \mathrm{P}$ MRS data were analysed as described previously (33). In short, spectra were fitted in the time domain by using a non-linear least-squares algorithm (AMARES) in the jMRUI software package (40). $\mathrm{PCr}$, inorganic phosphate $\left(\mathrm{P}_{\mathrm{i}}\right)$, ATP and phosphodiester (PDE) signals were fitted to the Lorentzian line shapes. Absolute concentrations of the phosphorylated metabolites were calculated after correction for partial saturation and assuming that the ATP concentration is $8.2 \mathrm{mM}$ at rest (42). Intracellular $\mathrm{pH}$ was calculated from the chemical shift difference between the $\mathrm{P}_{\mathrm{i}}$ and $\mathrm{PCr}$ resonances (43). The free cytosolic ADP concentration was calculated from the $\mathrm{PCr}$ concentration and $\mathrm{pH}$ using a creatine kinase equilibrium constant $\left(K_{\mathrm{eq}}\right)$ of $1.66 \times 10^{9} / \mathrm{M}(44)$. Recoveries of PCr and ADP were fitted to monoexponential functions using Matlab (version 7.30., Mathworks, Natick, MA, USA). Results are expressed as the metabolite's time constant of recovery, i.e. $\tau_{\mathrm{PCr}}$ and $\tau_{\text {ADP }}$, both of which are measures of the mitochondrial function $(43,45,46)$. Calculation of the initial rate of $\mathrm{PCr}$ recovery $\left(V_{\mathrm{PCr}}\right)$ was based on the $\mathrm{PCr}$ recovery rate $\left(1 / \tau_{\mathrm{PCr}}\right)$ and the difference between the resting and end-exercise $\mathrm{PCr}$ concentrations (47). Calculation of the maximum aerobic capacity $\left(Q_{\max }\right)$ was based on the ADP-control model (48), in which $V_{\mathrm{PCr}}$ has a hyperbolic dependence on the end-exercise ADP concentration according to Michaelis-Menten kinetics with a $K_{\mathrm{m}}$ of $30 \mu \mathrm{M}(47)$. 


\section{Statistical analysis}

All data are expressed as means \pm s.D. Statistical analyses were performed using the SPSS 14.0 software package (SPSS Inc., Chicago, IL, USA). An ANOVA test was performed to test for overall differences between the Control, pre-Diabetes and Diabetes groups and a Bonferroni post hoc test was applied for pairwise comparisons between the three groups. For comparisons between two groups, differences were determined with an unpaired $t$-test. To evaluate the relationships between variables, Pearson correlation coefficients were calculated. All tests were carried out in a two-sided way and the level of significance was set at $P<0.05$.

\section{Results}

\section{Subjects' characteristics}

The subjects' characteristics are shown in Table 1. Subjects were carefully matched for age and BMI. In accordance, FFM and truncal fat mass did not differ between the Control, pre-Diabetes and Diabetes groups $\left(P=0.29\right.$ and $P=0.87$ respectively). $W_{\text {max }}$ and $\mathrm{VO}_{2 \text { peak }}$ were similar for the Control and pre-Diabetes groups $(P=1.00)$, but significantly lower in the Diabetes group. The latter was paralleled by a lower maximal heart rate and a lower habitual physical activity level, but the physical activity levels were not significantly different between groups $(P=0.12)$. $W_{\text {max }}$ and $\mathrm{VO}_{2 \text { peak }}$ correlated with both maximal heart rate (Pearson's $R$ between 0.59 and 0.68 , $P<0.01)$ and percentage of the age-predicted maximal heart rate (Pearson's $R$ between 0.56 and $0.62, P<0.01$ ).

The fasting plasma glucose and insulin levels were not significantly different for the Control and pre-Diabetes groups $(P=0.39$ and $P=0.14$ respectively), but the HOMA index was significantly higher for the pre-Diabetes group than for the Control group. Also, the glucose and insulin concentrations measured $2 \mathrm{~h}$ after ingestion of the glucose load during the OGTT were significantly higher for the pre-Diabetes group than for the Control group. The $\mathrm{HbA}_{1 \mathrm{c}}$ contents were similar for the Control and preDiabetes groups $(P=1.00)$ and all subjects had $\mathrm{HbA}_{1 \mathrm{c}}$ contents below $6 \%$. The fasting glucose concentrations and $\mathrm{HbA}_{1 \mathrm{c}}$ contents were significantly higher in the Diabetes group (glucose $\geq 8 \mathrm{mmol} / \mathrm{l}$ and $\mathrm{HbA}_{1 \mathrm{c}} \geq 6.3 \%$ ) when compared with the Control and pre-Diabetes groups. Diabetes patients had been diagnosed with type 2 diabetes for $12 \pm 7$ years and had been on exogenous insulin therapy for $7 \pm 8$ years. Plasma NEFA concentrations did not differ between groups $(P=0.16)$.

$W_{\text {max }}$ and $\mathrm{VO}_{2 \text { peak }}$ correlated negatively with both fasting plasma glucose (Pearson's $R$ between -0.48 and $-0.57, P<0.01$ ) and $\mathrm{HbA}_{1 \mathrm{c}}$ (Pearson's $R$ between -0.58 and $-0.70, P<0.01)$.

\section{IMCL content}

Due to excessive EMCL contamination in the spectra, IMCL content could not be determined for two subjects

Table 1 Subjects' characteristics.

\begin{tabular}{|c|c|c|c|}
\hline & Control & pre-Diabetes & Diabetes \\
\hline$n$ & 12 & 11 & 10 \\
\hline Age (years) & $56.5 \pm 6.0$ & $58.5 \pm 5.0$ & $58.8 \pm 7.6$ \\
\hline BMl $\left(\mathrm{kg} / \mathrm{m}^{2}\right)$ & $32.9 \pm 4.6$ & $32.1 \pm 3.2$ & $31.8 \pm 4.0$ \\
\hline Body weight (kg) & $101.0 \pm 14.7$ & $103.9 \pm 10.0$ & $95.0 \pm 14.4$ \\
\hline FFM $(\mathrm{kg})$ & $70.7 \pm 7.1$ & $72.4 \pm 6.9$ & $67.2 \pm 8.4$ \\
\hline Truncal fat mass $(\mathrm{kg})$ & $15.5 \pm 5.5$ & $16.3 \pm 2.9$ & $15.4 \pm 4.5$ \\
\hline$W_{\max }(\mathrm{W})$ & $247 \pm 42$ & $244 \pm 30$ & $156 \pm 38^{*, \dagger}$ \\
\hline$W_{\max }$ per kg BW $(\mathrm{W} / \mathrm{kg})$ & $2.48 \pm 0.47$ & $2.39 \pm 0.47$ & $1.66 \pm 0.36^{*, \dagger}$ \\
\hline $\mathrm{VO}_{2 \text { peak per } \mathrm{kg} \mathrm{BW}}(\mathrm{ml} / \mathrm{min}$ per $\mathrm{kg})$ & $32.3 \pm 5.4$ & $33.8 \pm 5.9$ & $25.2 \pm 3.5^{\star, \dagger}$ \\
\hline $\mathrm{VO}_{\text {2peak per kg FFM }}(\mathrm{ml} / \mathrm{min}$ per $\mathrm{kg})$ & $45.6 \pm 6.0$ & $48.5 \pm 8.3$ & $35.5 \pm 5.2^{*, \dagger}$ \\
\hline $\mathrm{HR}_{\max }(\mathrm{b} / \mathrm{min})$ & $166 \pm 13$ & $171 \pm 12$ & $140 \pm 23^{*}, \dagger$ \\
\hline$\%$ predicted $\mathrm{HR}_{\max }$ & $99 \pm 8$ & $103 \pm 7$ & $84 \pm 14^{*, \dagger}$ \\
\hline Activity level (MET h/day) & $19.3 \pm 7.4$ & $19.5 \pm 8.7$ & $13.6 \pm 4.3$ \\
\hline Fasting glucose $(\mathrm{mmol} / \mathrm{l})$ & $5.7 \pm 0.2$ & $6.6 \pm 0.5$ & $11.0 \pm 2.5^{\star, \dagger}$ \\
\hline Fasting insulin $(\mu \mathrm{U} / \mathrm{ml})$ & $16.2 \pm 9.1$ & $22.2 \pm 9.6$ & ND \\
\hline HOMA index & $4.1 \pm 2.2$ & $6.5 \pm 2.7^{\ddagger}$ & ND \\
\hline 2-h glucose (mmol/l) & $5.7 \pm 1.3$ & $8.4 \pm 2.6^{\S}$ & ND \\
\hline 2-h insulin $(\mu \mathrm{U} / \mathrm{ml})$ & $74.8 \pm 40.5$ & $146.2 \pm 64.5^{\S}$ & ND \\
\hline $\mathrm{HbA}_{1 \mathrm{c}}(\%)$ & $5.3 \pm 0.3$ & $5.5 \pm 0.2$ & $7.7 \pm 1.0^{\star, \dagger}$ \\
\hline NEFA $(\mathrm{mmol} / \mathrm{l})$ & $0.31 \pm 0.10$ & $0.39 \pm 0.13$ & $0.46 \pm 0.26$ \\
\hline Years with type 2 diabetes & NA & NA & $12 \pm 7$ \\
\hline Years of insulin therapy & NA & NA & $7 \pm 8$ \\
\hline
\end{tabular}

Data are expressed as means \pm s.D. BMI, body mass index; FFM, fat-free mass; $W_{\max }$, maximal workload capacity; $W_{\max }$ per kg BW, $W_{\text {max }}$ per kg body weight; $\mathrm{VO}_{2 \text { peak }}$, maximal oxygen uptake capacity per $\mathrm{kg}$ body weight or per $\mathrm{kg} \mathrm{FFM} ; \mathrm{HR}_{\text {max }}$, maximal heart rate during the $\mathrm{VO}_{2 \text { peak }}$ test; \% predicted $\mathrm{HR}_{\text {max }}$, percentage of the age-predicted $\mathrm{HR}_{\max }$; MET, metabolic equivalents; HOMA, homeostasis model assessment; $2 \mathrm{~h}$ glucose/insulin, glucose/insulin concentration $2 \mathrm{~h}$ after ingestion of glucose load during the oral glucose tolerance test; $\mathrm{HbA}_{1 \mathrm{c}}$, glycosylated haemoglobin; NEFA, non-esterified fatty acids; NA, not applicable; ND, not determined. *Significantly different from Control (ANOVA, $P<0.01)$. ${ }^{\dagger}$ Significantly different from pre-Diabetes (ANOVA, $P<0.01$ ). ${ }^{\ddagger}$ Significantly different from Control $(t$-test, $P<0.05)$. ${ }^{\$}$ Significantly different from Control $(t$-test, $P<0.01)$. 
in the Control group and one subject in the Diabetes group. For all other subjects, spectra from at least two out of the five voxels were quantified. IMCL content tended to be higher for the Diabetes group when compared with the Control group $(1.3 \pm 0.4(n=10)$, $1.6 \pm 0.7(n=11)$ and $2.0 \pm 0.7(n=9) \%$ of the water signal in Control, pre-Diabetes and Diabetes groups respectively, $P=0.06$; Fig. 2 ).

\section{Skeletal muscle mitochondrial function}

Figure $3 \mathrm{~A}$ and $\mathrm{B}$ show typical examples of ${ }^{31} \mathrm{P} \mathrm{MR}$ spectra from a subject's vastus lateralis muscle at rest and at the end of exercise respectively. Table 2 summarizes the baseline, end-exercise and recovery ${ }^{31} \mathrm{P}$ MRS results for the Control, pre-Diabetes and Diabetes groups. At rest, $\mathrm{PCr}, \mathrm{P}_{\mathrm{i}}, \mathrm{ADP}$ and $\mathrm{PDE}$ concentrations and intracellular $\mathrm{pH}$ were not significantly different for the Control, pre-Diabetes and Diabetes groups $(P=0.93, P=0.50, \quad P=0.09$, $P=0.42$ and $P=0.10$ respectively). The end-exercise status has to be taken into account when analysing the recovery data. The end-exercise metabolite concentrations were similar for the three groups, except for the end-exercise ADP concentration, which was lower in the Diabetes group. However, for all groups, the endexercise ADP concentration was well above the accepted $K_{\mathrm{m}}$ value of $30 \mu \mathrm{M}$ for oxidative ATP synthesis. The average $\mathrm{PCr}$ depletion was $54 \pm 10,56 \pm 7$ and $46 \pm 8 \%$ for Control, pre-Diabetes and Diabetes groups respectively. For none of the subjects did the end-exercise $\mathrm{pH}$

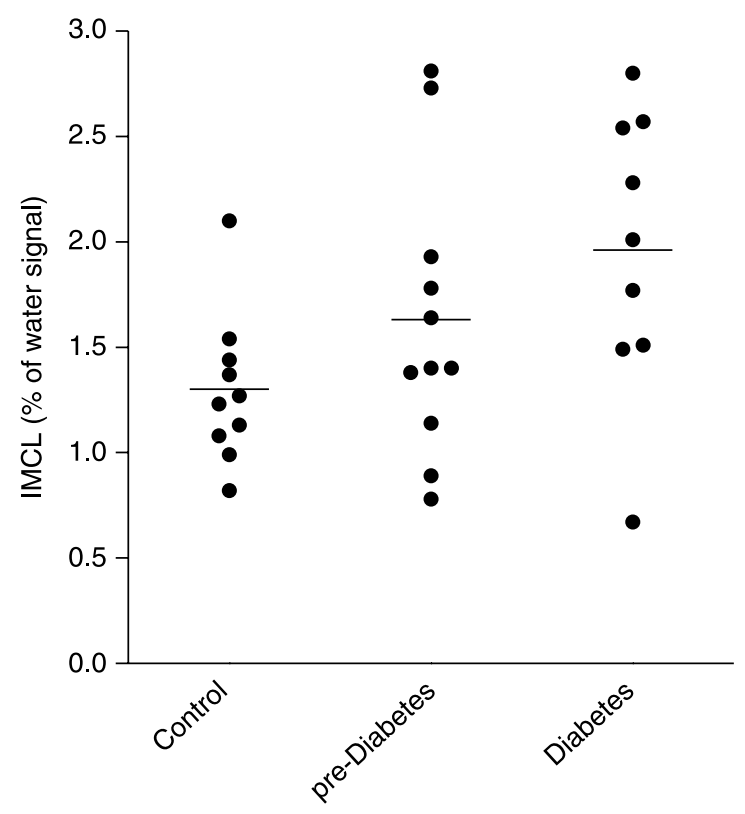

Figure $2 \mathrm{IMCL}$ content in Control, pre-Diabetes and Diabetes groups. Bars indicate the mean values for the three groups and filled circles represent the individual data points. IMCL content tended to be higher for the Diabetes group when compared with the Control group (ANOVA, $P=0.06$ ).
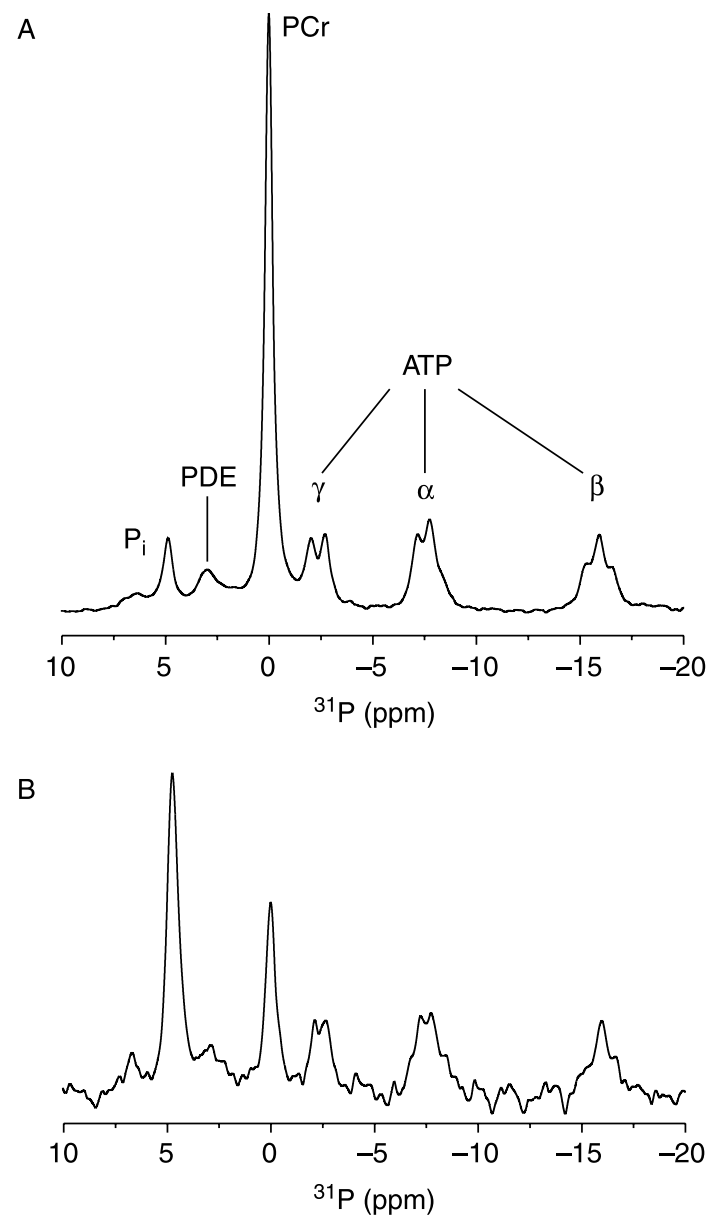

Figure 3 Typical $M$. vastus lateralis ${ }^{31} \mathrm{P}$ MR spectra for a normoglycaemic control subject at rest $(A$, number of scans $=60)$ and at the end of exercise $(B$, number of scans $=2)$. Spectra were processed with $5 \mathrm{~Hz}$ line broadening. $\mathrm{P}_{\mathrm{i}}$, inorganic phosphate; PDE, phosphodiesters; PCr, phosphocreatine; $\alpha, \beta$ and $\gamma$, the three phosphate groups of ATP. For this subject, the PCr depletion at the end of exercise (B) was $61 \%$ and the corresponding end-exercise $\mathrm{pH}$ was 6.96.

drop below 6.75. The average end-exercise $\mathrm{pH}$ was not different for the three groups $(P=0.72)$, which is a prerequisite for comparing $\tau_{\mathrm{PCr}}$

The $\mathrm{PCr}$ and ADP recoveries could be satisfactorily described by mono-exponential functions (average $R^{2}$ values for the mono-exponential fits were $0.96 \pm 0.02$ and $0.91 \pm 0.06$ for $\mathrm{PCr}$ and $\mathrm{ADP}$ recovery data respectively). Figure 4 illustrates both the raw data and mono-exponential fits of the $\mathrm{PCr}$ and $\mathrm{ADP}$ recoveries for one subject. Figure 5 shows the mean values and the distribution of $\tau_{\mathrm{PCr}}$ and $Q_{\max }$ for the Control, pre-Diabetes and Diabetes groups. The ${ }^{31} \mathrm{P}$ MRS parameters for mitochondrial function, i.e. $\tau_{\mathrm{PCr}}, \tau_{\mathrm{ADP}}$ and $Q_{\max }$, did not differ between the Control, preDiabetes and Diabetes groups $(P=0.62, P=0.29$ and $P=0.24$ respectively; Table 2$). V_{\mathrm{PCr}}$ was significantly lower for the Diabetes group when compared with the 
Table $2{ }^{31} \mathrm{P}$ MRS parameters during rest, end of exercise and recovery.

\begin{tabular}{lccc}
\hline & Control & pre-Diabetes & Diabetes \\
\hline Rest & & & \\
{$[\mathrm{PCr}](\mathrm{mM})$} & $37.3 \pm 2.3$ & $37.7 \pm 2.6$ & $37.2 \pm 4.2$ \\
{$\left[\mathrm{P}_{\mathrm{i}}\right](\mathrm{mM})$} & $4.8 \pm 0.6$ & $5.0 \pm 0.7$ & $4.7 \pm 0.8$ \\
{$[\mathrm{ADP}](\mu \mathrm{M})$} & $10.0 \pm 0.3$ & $10.4 \pm 0.5$ & $10.1 \pm 0.4$ \\
{$[\mathrm{PDE}](\mathrm{mM})$} & $6.0 \pm 0.8$ & $6.0 \pm 0.9$ & $5.5 \pm 0.9$ \\
$\mathrm{pH}$ & $7.06 \pm 0.01$ & $7.07 \pm 0.02$ & $7.06 \pm 0.02$ \\
End-exercise & & & \\
{$[\mathrm{PCr}](\mathrm{mM})$} & $16.9 \pm 3.5$ & $16.7 \pm 2.8$ & $20.0 \pm 4.5$ \\
{$\left[\mathrm{P}_{\mathrm{i}}\right](\mathrm{mM})$} & $23.3 \pm 4.9$ & $24.2 \pm 3.5$ & $19.8 \pm 4.0$ \\
{$[\mathrm{ADP}](\mu \mathrm{M})$} & $68.2 \pm 18.2$ & $70.2 \pm 11.3$ & $47.0 \pm 10.4^{*, \dagger}$ \\
$\mathrm{pH}$ & $6.91 \pm 0.08$ & $6.92 \pm 0.07$ & $6.89 \pm 0.12$ \\
$\mathrm{Recovery}$ & & & \\
$\tau_{\mathrm{PCr}}(\mathrm{s})$ & $44.5 \pm 10.5$ & $41.7 \pm 6.2$ & $46.6 \pm 16.5$ \\
$\tau_{\mathrm{ADP}}(\mathrm{s})$ & $19.1 \pm 3.5$ & $16.9 \pm 5.0$ & $20.2 \pm 6.0$ \\
$V_{\mathrm{PCr}}(\mathrm{mM} / \mathrm{s})$ & $0.47 \pm 0.09$ & $0.51 \pm 0.08$ & $0.39 \pm 0.09^{\dagger}$ \\
$Q_{\max }(\mathrm{mM} / \mathrm{s})$ & $0.69 \pm 0.12$ & $0.74 \pm 0.11$ & $0.65 \pm 0.13$ \\
\hline
\end{tabular}

Data are expressed as means \pm s.D. $P C r$, phosphocreatine; $P_{i}$, inorganic phosphate; ADP, adenosine diphosphate; PDE, phosphodiesters; $\mathrm{pH}$, intracellular muscle $\mathrm{pH} ; \tau_{\mathrm{PCr}}, \mathrm{PCr}$ recovery time constant; $\tau_{\mathrm{ADP}}$, ADP recovery time constant; $V_{\mathrm{PCr}}$, initial rate of $\mathrm{PCr}$ recovery; $Q_{\max }$, maximum rate of oxidative ATP synthesis. *Significantly different from Control (ANOVA, $P<0.01$ ). ${ }^{\dagger}$ Significantly different from pre-Diabetes (ANOVA, $P<0.01$ ).

pre-Diabetes group as a result of the lower end-exercise ADP concentration.

All ${ }^{31} \mathrm{P}$ MRS parameters for mitochondrial function correlated significantly with both $W_{\max }$ (absolute Pearson's $R$ between 0.45 and $0.60, P<0.01$ ) and $\mathrm{VO}_{2 \text { peak }}$ (absolute Pearson's $R$ between 0.35 and 0.59 , $P<0.05)$. However, $\tau_{\mathrm{PCr}}, \tau_{\mathrm{ADP}}$ and $Q_{\max }$ did not correlate with fasting plasma glucose or $\mathrm{HbA}_{1 \mathrm{c}}$.

\section{Discussion}

In this study, it was shown that in vivo skeletal muscle oxidative capacity, as determined from post-exercise $\mathrm{PCr}$ recovery kinetics using ${ }^{31} \mathrm{P}$ MRS, does not differ between long-standing, insulin-treated type 2 diabetes patients, subjects with early stage type 2 diabetes and healthy, normoglycaemic controls, all matched for age and body composition and with low habitual physical activity levels. Therefore, our results suggest that skeletal muscle mitochondrial dysfunction does not necessarily represent either cause or consequence of type 2 diabetes.

Maximal workload capacity and maximal wholebody oxygen uptake capacity were significantly lower in the type 2 diabetes patients and correlated negatively with both plasma glucose and blood $\mathrm{HbA}_{1 \mathrm{c}}$ contents. The ${ }^{31} \mathrm{P}$ MRS recovery parameters, $\tau_{\mathrm{PCr}} \tau_{\mathrm{ADP}}$ and $Q_{\mathrm{max}}$, correlated significantly with $W_{\max }$ and $\mathrm{VO}_{2 \text { peak }}$, but not with plasma glucose or blood $\mathrm{HbA}_{1 \mathrm{c}}$ levels. Therefore, $W_{\text {max }}$ and $\mathrm{VO}_{2 \text { peak }}$ seem to represent markers of the disease status, whereas $\tau_{\mathrm{PCr}}, \tau_{\mathrm{ADP}}$ and $Q_{\max }$ report only on local muscle mitochondrial function. The Pearson correlation coefficient for the correlation between $Q_{\max }$ and $\mathrm{VO}_{2 \text { peak }}$ per $\mathrm{kg}$ FFM $\left(\mathrm{VO}_{2 \text { peak per kg FFM }}\right)$ was 0.47
A

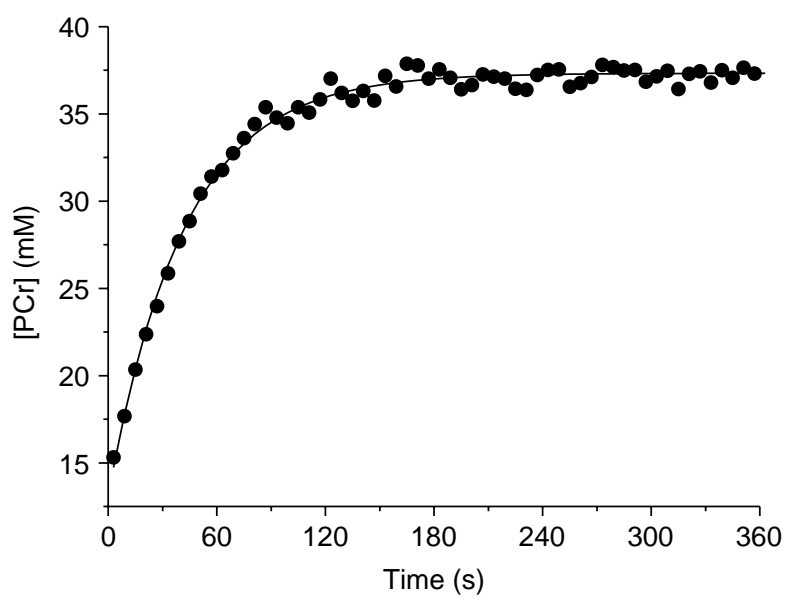

B

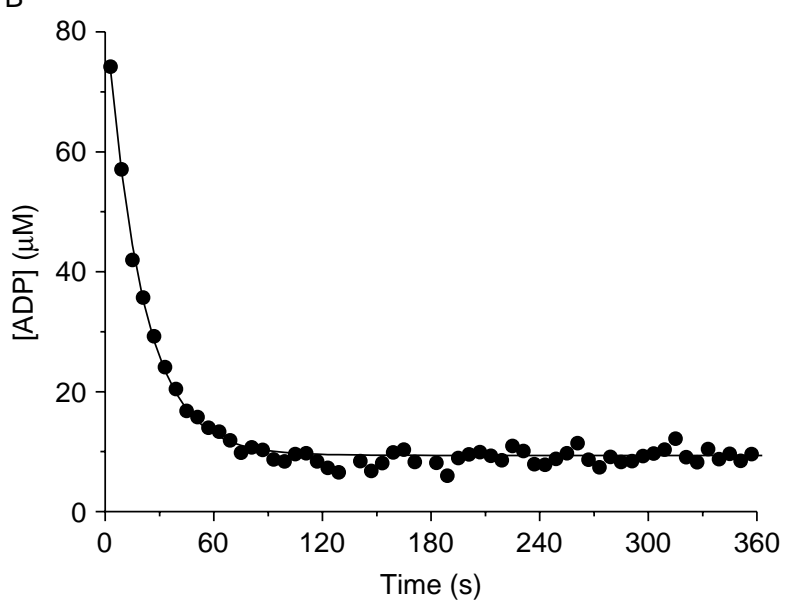

Figure 4 (A) $\mathrm{PCr}$ and (B) ADP recovery curves from the data set that were also used in Fig. 3. Mono-exponential functions (dark lines) were fit to the actual data (filled circles) obtained every $6 \mathrm{~s}$. The time constants for $\mathrm{PCr}$ and ADP recovery were 41.8 and $19.8 \mathrm{~s}$ respectively.

$\left(R^{2}=0.22\right)$. Therefore, only $22 \%$ of the variance in $\mathrm{VO}_{2 \text { peak per kg FFM }}$ can be explained by $Q_{\text {max }} \cdot Q_{\max }$ was measured locally in the M. vastus lateralis during a dynamic single-leg extension exercise, while wholebody $\mathrm{VO}_{2 \text { peak }}$ was determined on a cycle ergometer. The remaining variance in $\mathrm{VO}_{2 \text { peak }}$ per $\mathrm{kg}$ FFM could be accounted for by differences in cardiovascular capacity at peak work rates that are not expected to play a significant role during the local exercise in the MR scanner. The apparent discrepancy between the results for $Q_{\max }$ and $\mathrm{VO}_{2 \text { peak }}$ per $\mathrm{kg}$ FFM might therefore be explained by differences in cardiac output. The latter concept seems to be supported by a significant correlation between the maximal heart rate and $\mathrm{VO}_{2 \text { peak }}$ per kg FFM (Pearson's $R=0.64, P<0.01$ ).

In this study, ${ }^{31} \mathrm{P}$ MRS was applied to assess in vivo skeletal muscle mitochondrial function from measurements during recovery from exercise. During recovery 
A

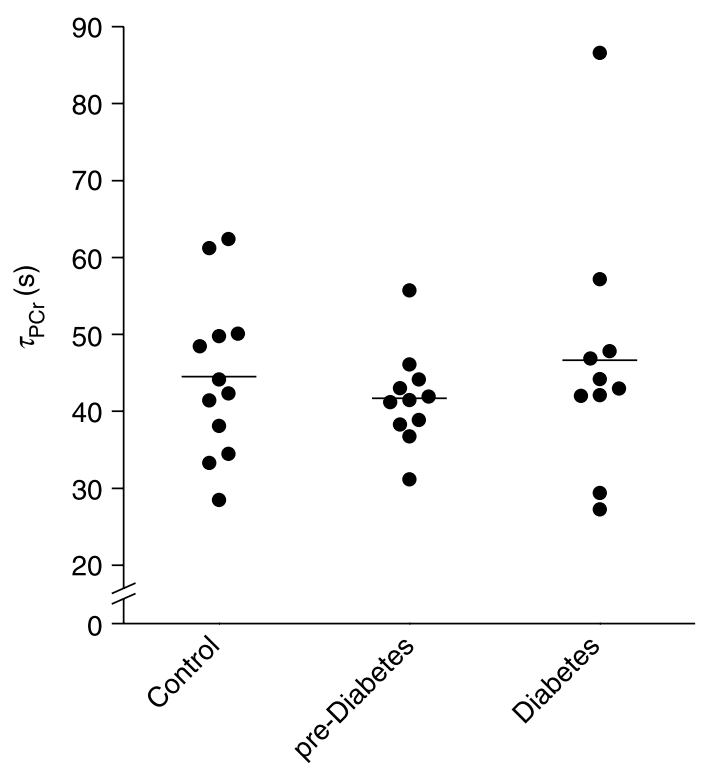

B

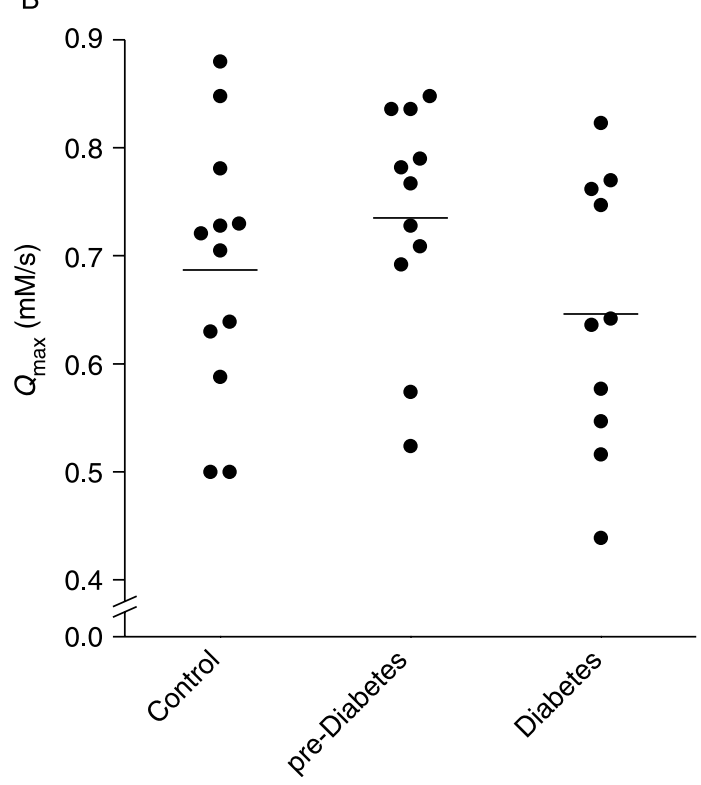

Figure 5 (A) $\tau_{\mathrm{PCr}}$ and (B) $Q_{\max }$ in Control, pre-Diabetes and Diabetes groups. Bars indicate the mean values for the three groups and filled circles represent the individual data points. $\tau_{\mathrm{PCr}}$ and $Q_{\max }$ were not significantly different between Control, pre-Diabetes and Diabetes groups (ANOVA, $P=0.62$ and $P=0.24$ respectively).

from exercise, $\mathrm{PCr}$ is resynthesized purely as a consequence of oxidative ATP synthesis $(43,45)$. Therefore, $\tau_{\mathrm{PCr}}$ provides information about mitochondrial function. Recently, Schrauwen-Hinderling et al. applied the same technique to study mitochondrial function in the M. vastus lateralis in overweight type 2 diabetes patients and BMI-matched control subjects (19). Contrary to our results, $\tau_{\mathrm{PCr}}$ was $45 \%$ longer in the type 2 diabetes group when compared with the control group (i.e. $39.4 \pm 17.5$ vs $27.0 \pm 3.9$ s), suggestive of impaired in vivo mitochondrial function in the type 2 diabetes patients. It should be noted that different exercise protocols were chosen for the ${ }^{31} \mathrm{P}$ MRS measurements in the two studies. We applied an exercise protocol that progressively increased work to deplete $\mathrm{PCr}$ by about 50\% without severe acidification. In the previous study, exercise was performed with a single load, until a steady state was reached with an average PCr depletion of $28 \%$. The larger PCr depletion in the current study was accompanied by a slightly larger drop in $\mathrm{pH}$ (change in $\mathrm{pH}$ was on average 0.16 in this study versus 0.04 in (19)). Several studies have shown that PCr recovery is slowed down in the presence of intracellular acidosis $(30,49,50)$. However, we carefully matched the end-exercise $\mathrm{pH}$ for the Control, pre-Diabetes and Diabetes groups, to allow a direct comparison of $\tau_{\mathrm{PCr}}$ between groups. As an alternative to $\tau_{\mathrm{PCr}}$, both $\tau_{\mathrm{ADP}}$ and $Q_{\max }$ can also be used to assess in vivo mitochondrial function and these parameters have been shown to be independent of $\mathrm{pH}(30,50-53)$. In accordance with the $\tau_{\mathrm{PCr}}$ data matched for end-exercise $\mathrm{pH}, \tau_{\mathrm{ADP}}$ and $Q_{\max }$ also did not differ between groups.

As suggested in the literature, $\tau_{\mathrm{PCr}}$ can be normalized for $\mathrm{pH}$ using a correction factor of $-46 \mathrm{~s}$ per $\mathrm{pH}$ unit (49). Recalculating the values from Schrauwen-Hinderling et al. to a 0.12 lower end-exercise $\mathrm{pH}$ results in $\tau_{\mathrm{PCr}}$ 's of about 45 and $32 \mathrm{~s}$ for the type 2 diabetes and control group respectively. This implies that the mitochondrial function in our Control, pre-Diabetes and Diabetes groups is similar to that of the type 2 diabetes patients in the study of Schrauwen-Hinderling et al., but that the controls in the latter study show a greater mitochondrial oxidative capacity. For other studies in healthy, elderly subjects previously reported in the literature (54-56), average values for $\tau_{\mathrm{PCr}}$ (recalculated at an end-exercise $\mathrm{pH}$ of 6.9 if necessary) have been shown to range between 43 and $46 \mathrm{~s}$, which is well in line with the average $\tau_{\mathrm{PCr}}$ in our Control group. As such, muscle mitochondrial function in these overweight normoglycaemic control subjects does not seem to be substantially impaired.

As an alternative to measuring muscle oxidative capacity from dynamic ${ }^{31} \mathrm{P}$ MRS experiments after exercise, Petersen et al. applied ${ }^{31} \mathrm{P}$ MRS saturation transfer experiments to measure mitochondrial ATP synthesis rates in resting skeletal muscle of healthy, young, lean, insulin-resistant offspring of type 2 diabetes patients and insulin-sensitive control subjects matched for age, height, weight and physical activity (17). ATP synthesis rates were $\sim 30 \%$ lower in insulinresistant subjects than in controls and it was concluded that the insulin-resistant offspring might have an inherited defect in mitochondrial phosphorylation. However, as commented by Short et al. (24) and Wagenmakers (25), the lower ATP synthesis rates in insulin-resistant subjects could actually be caused by 
the impaired insulin signalling, jeopardizing insulindependent mitochondrial processes, rather than the reverse. This view is supported by studies that show that high-dose insulin infusions increase mRNA transcript levels of genes involved in mitochondrial function, mitochondrial protein synthesis and mitochondrial ATP production rates in healthy people, but not in the type 2 diabetes patients $(28,57,58)$. In summary, it seems likely that the decreased basal ATP synthesis rates in insulin resistant subjects are a result of the decreased insulin sensitivity and do not necessarily reflect any intrinsic mitochondrial defect.

The diabetes patients in the current study were on exogenous insulin treatment for more than 5 years and continued their medication during the study. As blood glucose and insulin levels can affect measurements of mitochondrial function $(27,28)$, the higher plasma insulin levels in the Diabetes group as a result of exogenous insulin treatment might be a confounding factor in this study. Despite the insulin treatment, our diabetes patients were still hyperglycaemic (fasting plasma glucose concentration: $11.0 \pm 2.5 \mathrm{mmol} / \mathrm{l}$ ). Therefore, hyperglycaemia might also have affected the measurement of in vivo muscle mitochondrial function in the diabetes patients.

Rabøl et al. recently reviewed the experimental data on mitochondrial dysfunction in type 2 diabetes and concluded that evidence of an intrinsic defect in the mitochondria of type 2 diabetes patients is far from convincing (23). Considering that type 2 diabetes patients are generally physically inactive, the impairments in oxidative metabolism in type 2 diabetes patients might simply be attributed to their sedentary lifestyle. In this regard, it is important to note that in most studies physical activity has not been (strictly) controlled for. For studies in which physical activity was taken into account, the results suggest that the abnormalities in oxidative metabolism in type 2 diabetes patients can at least partly be attributed to physical inactivity $(14,28,59,60)$. In accordance, recent data from respiration measurements on permeabilized muscle fibres show that when $\mathrm{O}_{2}$ flux is being normalized for mitochondrial DNA content or citrate synthase activity, no differences in mitochondrial respiration rate are observed between type 2 diabetes patients and healthy controls (21). These results imply that type 2 diabetes patients have normal intrinsic mitochondrial function, but an impaired oxidative capacity due to a reduced mitochondrial content, most likely secondary to lower habitual physical activity levels $(21,22)$. More recently, Turner et al. examined markers of muscle mitochondrial fatty acid oxidative capacity in rodent models of lipid-induced insulin resistance (61). Surprisingly, fatty acid oxidative capacity and protein expression of peroxisome proliferator-activated receptor- $\gamma$ coactivator $1 \alpha$ and mitochondrial respiratory chain subunits appeared to be upregulated. As such, the authors concluded that, at least in these rodent models, high lipid availability does not lead to intramuscular lipid accumulation and insulin resistance by decreasing muscle mitochondrial fatty acid oxidative capacity. In accordance, in the current study we observed no differences in in vivo muscle mitochondrial function between long-standing type 2 diabetes patients, subjects with early stage type 2 diabetes and sedentary, normoglycaemic controls.

In conclusion, subjects with early stage type 2 diabetes as well as long-standing, insulin-treated type 2 diabetes patients do not show signs of in vivo skeletal muscle mitochondrial dysfunction. The latter implies that mitochondrial dysfunction does not necessarily represent either cause or consequence of insulin resistance and/or type 2 diabetes. Impairments in oxidative metabolism in type 2 diabetes patients observed in previous studies are likely to be secondary to a less active lifestyle and/or impaired insulin signalling.

\section{Acknowledgements}

We are very grateful to Larry de Graaf for his technical assistance with the MR scanner.

\section{References}

1 Pan DA, Lillioja S, Kriketos AD, Milner MR, Baur LA, Bogardus C, Jenkins AB \& Storlien LH. Skeletal muscle triglyceride levels are inversely related to insulin action. Diabetes 199746 983-988.

2 Krssak M, Falk Petersen K, Dresner A, Dipietro L, Vogel SM, Rothman DL, Roden M \& Shulman GI. Intramyocellular lipid concentrations are correlated with insulin sensitivity in humans: a 1H NMR spectroscopy study. Diabetologia 199942 113-116.

3 Van Loon LJ, Koopman R, Manders R, Van Der Weegen W, Van Kranenburg GP \& Keizer HA. Intramyocellular lipid content in type 2 diabetes patients compared with overweight sedentary men and highly trained endurance athletes. American Journal of Physiology. Endocrinology and Metabolism 2004287 E558-E565.

4 Van Loon LJ \& Goodpaster BH. Increased intramuscular lipid storage in the insulin-resistant and endurance-trained state. Pflugers Archiv $2006 \mathbf{4 5 1}$ 606-616.

5 Morino K, Petersen KF \& Shulman GI. Molecular mechanisms of insulin resistance in humans and their potential links with mitochondrial dysfunction. Diabetes $2006 \mathbf{5 5}$ (Suppl 2) S9-S15.

6 Simoneau JA \& Kelley DE. Altered glycolytic and oxidative capacities of skeletal muscle contribute to insulin resistance in NIDDM. Journal of Applied Physiology 199783 166-171.

7 He J, Watkins S \& Kelley DE. Skeletal muscle lipid content and oxidative enzyme activity in relation to muscle fiber type in type 2 diabetes and obesity. Diabetes $200150817-823$.

8 Kelley DE, He J, Menshikova EV \& Ritov VB. Dysfunction of mitochondria in human skeletal muscle in type 2 diabetes. Diabetes $2002512944-2950$.

9 Ritov VB, Menshikova EV, He J, Ferrell RE, Goodpaster BH \& Kelley DE. Deficiency of subsarcolemmal mitochondria in obesity and type 2 diabetes. Diabetes $2005 \mathbf{5 4} 8-14$.

10 Heilbronn LK, Gan SK, Turner N, Campbell LV \& Chisholm DJ. Markers of mitochondrial biogenesis and metabolism are lower in overweight and obese insulin-resistant subjects. Journal of Clinical Endocrinology and Metabolism 200792 1467-1473.

11 Mootha VK, Lindgren CM, Eriksson KF, Subramanian A, Sihag S, Lehar J, Puigserver P, Carlsson E, Ridderstrale M, Laurila E, 
Houstis N, Daly MJ, Patterson N, Mesirov JP, Golub TR, Tamayo P, Spiegelman B, Lander ES, Hirschhorn JN, Altshuler D \& Groop LC. PGC-1alpha-responsive genes involved in oxidative phosphorylation are coordinately downregulated in human diabetes. Nature Genetics 200334 267-273.

12 Patti ME, Butte AJ, Crunkhorn S, Cusi K, Berria R, Kashyap S, Miyazaki Y, Kohane I, Costello M, Saccone R, Landaker EJ, Goldfine AB, Mun E, Defronzo R, Finlayson J, Kahn CR \& Mandarino LJ. Coordinated reduction of genes of oxidative metabolism in humans with insulin resistance and diabetes: potential role of PGCl and NRF1. PNAS 2003100 8466-8471.

13 Hojlund K, Wrzesinski K, Larsen PM, Fey SJ, Roepstorff P, Handberg A, Dela F, Vinten J, Mccormack JG, Reynet C \& BeckNielsen H. Proteome analysis reveals phosphorylation of ATP synthase beta -subunit in human skeletal muscle and proteins with potential roles in type 2 diabetes. Journal of Biological Chemistry 2003278 10436-10442.

14 Morino K, Petersen KF, Dufour S, Befroy D, Frattini J, Shatzkes N, Neschen S, White MF, Bilz S, Sono S, Pypaert M \& Shulman GI. Reduced mitochondrial density and increased IRS-1 serine phosphorylation in muscle of insulin-resistant offspring of type 2 diabetic parents. Journal of Clinical Investigation 2005115 3587-3593.

15 Mogensen M, Sahlin K, Fernstrom M, Glintborg D, Vind BF, BeckNielsen H \& Hojlund K. Mitochondrial respiration is decreased in skeletal muscle of patients with type 2 diabetes. Diabetes $2007 \mathbf{5 6}$ 1592-1599.

16 Petersen KF, Befroy D, Dufour S, Dziura J, Ariyan C, Rothman DL, Dipietro L, Cline GW \& Shulman GI. Mitochondrial dysfunction in the elderly: possible role in insulin resistance. Science $2003 \mathbf{3 0 0}$ 1140-1142.

17 Petersen KF, Dufour S, Befroy D, Garcia R \& Shulman GI. Impaired mitochondrial activity in the insulin-resistant offspring of patients with type 2 diabetes. New England Journal of Medicine 2004350 664-671.

18 Szendroedi J, Schmid AI, Chmelik M, Toth C, Brehm A, Krssak M, Nowotny P, Wolzt M, Waldhausl W \& Roden M. Muscle mitochondrial ATP synthesis and glucose transport/phosphorylation in type 2 diabetes. PLoS Medicine 20074 e154.

19 Schrauwen-Hinderling VB, Kooi ME, Hesselink MK, Jeneson JA, Backes WH, Van Echteld CJ, Van Engelshoven JM, Mensink M \& Schrauwen P. Impaired in vivo mitochondrial function but similar intramyocellular lipid content in patients with type 2 diabetes mellitus and BMI-matched control subjects. Diabetologia 200750 $113-120$.

20 Sirikul B, Gower BA, Hunter GR, Larson-Meyer DE \& Newcomer BR. Relationship between insulin sensitivity and in vivo mitochondrial function in skeletal muscle. American Journal of Physiology. Endocrinology and Metabolism 2006291 E724-E728.

21 Boushel R, Gnaiger E, Schjerling P, Skovbro M, Kraunsoe R \& Dela F. Patients with type 2 diabetes have normal mitochondrial function in skeletal muscle. Diabetologia 200750 790-796.

22 Hawley JA \& Lessard SJ. Mitochondrial function: use it or lose it. Diabetologia 200750 699-702.

23 Rabol R, Boushel R \& Dela F. Mitochondrial oxidative function and type 2 diabetes. Applied Physiology, Nutrition, and Metabolism 2006 31 675-683.

24 Short KR, Nair KS \& Stump CS. Impaired mitochondrial activity and insulin-resistant offspring of patients with type 2 diabetes. New England Journal of Medicine 2004350 2419-2421 (author reply 2419-2421).

25 Wagenmakers AJ. Insulin resistance in the offspring of parents with type 2 diabetes. PLoS Medicine 20052 e289.

26 Brehm A, Krssak M, Schmid AI, Nowotny P, Waldhausl W \& Roden M. Increased lipid availability impairs insulin-stimulated ATP synthesis in human skeletal muscle. Diabetes $2006 \mathbf{5 5}$ 136-140.

27 Sreekumar R, Halvatsiotis P, Schimke JC \& Nair KS. Gene expression profile in skeletal muscle of type 2 diabetes and the effect of insulin treatment. Diabetes 200251 1913-1920.
28 Asmann YW, Stump CS, Short KR, Coenen-Schimke JM, Guo Z, Bigelow ML \& Nair KS. Skeletal muscle mitochondrial functions, mitochondrial DNA copy numbers, and gene transcript profiles in type 2 diabetic and nondiabetic subjects at equal levels of low or high insulin and euglycemia. Diabetes 200655 3309-3319.

29 Radda GK, Bore PJ, Gadian DG, Ross BD, Styles P, Taylor DJ \& Morgan-Hughes J. ${ }^{31} \mathrm{P}$ NMR, examination of two patients with NADH-CoQ reductase deficiency. Nature 1982295 608-609.

30 Arnold DL, Matthews PM \& Radda GK. Metabolic recovery after exercise and the assessment of mitochondrial function in vivo in human skeletal muscle by means of ${ }^{31} \mathrm{P}$ NMR. Magnetic Resonance in Medicine 19841 307-315.

31 Chance B, Im J, Nioka S \& Kushmerick M. Skeletal muscle energetics with PNMR: personal views and historic perspectives. NMR in Biomedicine 200619 904-926.

32 World Health Organization and International Diabetes Federation. Definition and Diagnosis of Diabetes Mellitus and Intermediate Hyperglycaemia: Report of a WHO/IDF Consultation Geneva, Switzerland: WHO Press, 2006.

33 Praet SF, Feyter HM, Jonkers RA, Nicolay K, Pul C, Kuipers H, Loon LJ \& Prompers JJ. (31)P MR spectroscopy and in vitro markers of oxidative capacity in type 2 diabetes patients. Magma 200619 321-331.

34 De Feyter HM, Praet SF, Van Den Broek NM, Kuipers H, Stehouwer CD, Nicolay K, Prompers JJ \& Van Loon LJ. Exercise training improves glycemic control in long-standing insulintreated type 2 diabetic patients. Diabetes Care 200730 2511-2513.

35 Montoye HJ, Kemper HCG, Saris WHM \& Washburn RA. Measuring Physical Activity and Energy Expenditure Champaign, Illinois: Human Kinetics, 1996.

36 Zhang YY, Johnson MC, II, Chow N \& Wasserman K. Effect of exercise testing protocol on parameters of aerobic function. Medicine and Science in Sports and Exercise 199123 625-630.

37 Weber CT, Janicki JS \& Mcelroy PA. Cardiopulmonary Exercise Testing (CPX) Testing Philadelphia: W. B. Saunders, 1986.

38 Gellish RL, Goslin BR, Olson RE, Mcdonald A, Russi GD \& Moudgil VK. Longitudinal modeling of the relationship between age and maximal heart rate. Medicine and Science in Sports and Exercise $200739822-829$.

39 Matthews DR, Hosker JP, Rudenski AS, Naylor BA, Treacher DF \& Turner RC. Homeostasis model assessment: insulin resistance and beta-cell function from fasting plasma glucose and insulin concentrations in man. Diabetologia 198528 412-419.

40 Vanhamme L, Van Den Boogaart A \& Van Huffel S. Improved method for accurate and efficient quantification of MRS data with use of prior knowledge. Journal of Magnetic Resonance 1997129 $35-43$.

41 Boesch C, Slotboom J, Hoppeler H \& Kreis R. In vivo determination of intra-myocellular lipids in human muscle by means of localized 1H-MR-spectroscopy. Magnetic Resonance in Medicine 199737 484-493.

42 Taylor DJ, Styles P, Matthews PM, Arnold DA, Gadian DG, Bore P \& Radda GK. Energetics of human muscle: exercise-induced ATP depletion. Magnetic Resonance in Medicine 19863 44-54.

43 Taylor DJ, Bore PJ, Styles P, Gadian DG \& Radda GK. Bioenergetics of intact human muscle. A ${ }^{31} \mathrm{P}$ nuclear magnetic resonance study. Molecular Biology and Medicine 19831 77-94.

44 Lawson JW \& Veech RL. Effects of $\mathrm{pH}$ and free $\mathrm{Mg}^{2+}$ on the Keq of the creatine kinase reaction and other phosphate hydrolyses and phosphate transfer reactions. Journal of Biological Chemistry 1979 254 6528-6537.

45 Quistorff B, Johansen L \& Sahlin K. Absence of phosphocreatine resynthesis in human calf muscle during ischaemic recovery. Biochemical Journal 1993291 681-686.

46 Kemp GJ \& Radda GK. Quantitative interpretation of bioenergetic data from ${ }^{31} \mathrm{P}$ and $1 \mathrm{H}$ magnetic resonance spectroscopic studies of skeletal muscle: an analytical review. Magnetic Resonance Quarterly 199410 43-63. 
47 Kemp GJ, Thompson CH, Barnes PR \& Radda GK. Comparisons of ATP turnover in human muscle during ischemic and aerobic exercise using ${ }^{31} \mathrm{P}$ magnetic resonance spectroscopy. Magnetic Resonance in Medicine 199431 248-258.

48 Chance B, Leigh JS, Jr, Clark BJ, Maris J, Kent J, Nioka S \& Smith D. Control of oxidative metabolism and oxygen delivery in human skeletal muscle: a steady-state analysis of the work/energy cost transfer function. PNAS $1985 \mathbf{8 2} 8384-8388$.

49 Iotti S, Lodi R, Frassineti C, Zaniol P \& Barbiroli B. In vivo assessment of mitochondrial functionality in human gastrocnemius muscle by ${ }^{31} \mathrm{P}$ MRS. The role of $\mathrm{pH}$ in the evaluation of phosphocreatine and inorganic phosphate recoveries from exercise. NMR in Biomedicine 19936 248-253.

50 Van den Broek NM, De Feyter HM, De Graaf L, Nicolay K \& Prompers JJ. Intersubject differences in the effect of acidosis on phosphocreatine recovery kinetics in muscle after exercise are due to differences in proton efflux rates. American Journal of Physiology. Cell Physiology 2007293 C228-C237.

51 Argov Z, De Stefano N \& Arnold DL. ADP recovery after a brief ischemic exercise in normal and diseased human muscle - a ${ }^{31} \mathrm{P}$ MRS study. NMR in Biomedicine 19969 165-172.

52 Lodi R, Kemp GJ, Iotti S, Radda GK \& Barbiroli B. Influence of cytosolic $\mathrm{pH}$ on in vivo assessment of human muscle mitochondrial respiration by phosphorus magnetic resonance spectroscopy. Magma 19975 165-171.

53 Roussel M, Bendahan D, Mattei JP, Le Fur Y \& Cozzone PJ. ${ }^{31} \mathrm{P}$ magnetic resonance spectroscopy study of phosphocreatine recovery kinetics in skeletal muscle: the issue of intersubject variability. Biochimica et Biophysica Acta 20001457 18-26.

54 Kent-Braun JA \& Ng AV. Skeletal muscle oxidative capacity in young and older women and men. Journal of Applied Physiology $2000891072-1078$.
55 Conley KE, Jubrias SA \& Esselman PC. Oxidative capacity and ageing in human muscle. Journal of Physiology $2000 \mathbf{5 2 6} 203-210$.

56 Scheuermann-Freestone M, Madsen PL, Manners D, Blamire AM, Buckingham RE, Styles P, Radda GK, Neubauer S \& Clarke K. Abnormal cardiac and skeletal muscle energy metabolism in patients with type 2 diabetes. Circulation 2003107 3040-3046.

57 Stump CS, Short KR, Bigelow ML, Schimke JM \& Nair KS. Effect of insulin on human skeletal muscle mitochondrial ATP production, protein synthesis, and mRNA transcripts. PNAS $2003 \mathbf{1 0 0}$ 7996-8001.

58 Petersen KF, Dufour S \& Shulman GI. Decreased insulin-stimulated ATP synthesis and phosphate transport in muscle of insulinresistant offspring of type 2 diabetic parents. PLoS Medicine 2005 2 e233.

59 Ortenblad N, Mogensen M, Petersen I, Hojlund K, Levin K, Sahlin K, Beck-Nielsen H \& Gaster M. Reduced insulin-mediated citrate synthase activity in cultured skeletal muscle cells from patients with type 2 diabetes: evidence for an intrinsic oxidative enzyme defect. Biochimica et Biophysica Acta 20051741 206-214.

60 Timmons JA, Norrbom J, Scheele C, Thonberg H, Wahlestedt C \& Tesch P. Expression profiling following local muscle inactivity in humans provides new perspective on diabetes-related genes. Genomics 200687 165-172.

61 Turner N, Bruce CR, Beale SM, Hoehn KL, So T, Rolph MS \& Cooney GJ. Excess lipid availability increases mitochondrial fatty acid oxidative capacity in muscle: evidence against a role for reduced fatty acid oxidation in lipid-induced insulin resistance in rodents. Diabetes 200756 2085-2092.

Received 29 January 2008

Accepted 4 February 2008 